\title{
Synthesis and properties of novel styrene acrylonitrile/polypropylene blends with enhanced toughness
}

\author{
Yi-jun Liao ${ }^{1}$, Xiao-li Wu' ${ }^{1}$ Lin Zhu ${ }^{2^{*}}$ and Tao Yi ${ }^{2^{*}}$
}

\begin{abstract}
Background: Although polypropylene (PP) has been widely used, its brittleness restricts even further applications.

Methods: In this study, we have used a melt blending process to synthesize styrene acrylonitrile (SAN)/PP blends containing 0, 5, 10, 15 and $20 \mathrm{wt} \%$ SAN. The effects of adding various amount of SAN on the blends characteristics, mechanical properties, thermal behavior and morphology were investigated.

Results: The results demonstrated that SAN had no obviously effect on crystal form but reduced the crystallinity of PP and increased the viscosity. The heat deflection temperature and Vicat softening temperature were enhanced for all SAN/PP blends, in particular for blends with low SAN content (5 and $10 \mathrm{wt} \%$ ). The morphology of SAN/PP blends with 10 wt\% SAN revealed the presence of nanoparticles dispersed on the surface, while SAN/PP blends with 20 wt $\%$ SAN exhibited the presence of spherical droplets and dark holes. All SAN/PP blends showed higher impact strength compared to pure PP, especially for SAN/PP blend containing $10 \mathrm{wt} \%$ SAN for which the impact strength was 2.3 times higher than that of pure PP.
\end{abstract}

Conclusions: The reason for significant increase in impact properties seemed to have a strong correlation with nanoparticles morphology and the decrease of PP crystallinity.

Keywords: Polypropylene, Styrene acrylonitrile, Nanoparticles, Toughness

\section{Background}

Thermoplastic polymers have been extensively used in our life duo to their advantages of recyclability, sustainability and superior properties [1]. Polypropylene (PP) is one of thermoplastic polymers, which has attracted considerable attention in the past decades owing to its outstanding mechanical properties, easy formation, excellent electrical insulation, high resistance to chemical agents, and environmental friendliness [2,3]. While PP has a variety of serious defects, such as large molding shrinkage, low notch impact resistance at low temperature, especially low resistance in crack propagation despite its high resistance to crack initiation [4, 5].

\footnotetext{
*Correspondence: linzhu912@gmail.com; yitao@hkbu.edu.hk 2 School of Chinese Medicine, Hong Kong Baptist University, Hong Kong, Special Administrative Region, People's Republic of China Full list of author information is available at the end of the article
}

Nowadays, the method of improving the toughness of polymers is mainly adding modifiers such as a plastic, an elastomer or a rigid body [6-9]. The combination of rubber or a thermoplastic elastomer with a polymer is one of the most effective toughening modifications; however, as the content of modifier increases, the elastic modulus, tensile strength and high-temperature creep deformation of the composites are significantly reduced $[10,11]$. In recent years, researches have been experimenting with adding rigid bodies to polymer blends to improve impact strength. The rigid bodies not only toughen the blends, but also enhance their overall physical properties for specific applications [12-15]. Adding organic rigid bodies to PP is a common method for increasing the impact resistance of PP, with appropriate modification of the interface [16, 17]. Use of the organic rigid bodies nylon-6 $[18,19]$, polymethyl methacrylate $[20,21]$ and acrylonitrile-butadiene-styrene 
(ABS) [22-25] has been frequently reported in recent years. Mai et al. [14] synthesized nine groups of polypropylene blends with different organic rigid bodies, demonstrating that polycarbonate/polymethyl methacrylate (PC/PMMA) could improve the impact strength of the PP matrix. Bonda et al. [16] synthesized ABS/PP blends with compatibilizers and demonstrated that the increase of impact strength was due to the rubber toughening effect of ABS. In contrast, blending the organic rigid body styrene acrylonitrile (SAN) with PP has been much less frequently reported.

SAN resins are copolymers of styrene (PS) and acrylonitrile (AN). ABS is a terpolymer of acrylonitrile, butadiene and styrene in which styrene provides rigidity and ease of processability, acrylonitrile supplies chemical resistance, rigidity and heat stability, and butadiene $(\mathrm{PB})$ supplies toughness and impact strength [26, 27]. SAN, without $\mathrm{PB}$, is brittle and has low impact strength, and is expected to be an organic rigid body that can enhance the impact strength of PP like inorganic particles [22]. There are two theories of reinforcement polymers matrix for inorganic particles, one is that adding inorganic rigid particles may cause changes in the distribution of the stress concentration in the polymer and yielding strength in some area under low stress, and finally result in the enhancement effect on impact strength of polymer. Another theory is that rigid particles resist the crack propagation of the polymer matrix, followed by making it being passivated and ultimately prevent the fissure developing into destructive cracking in the process of plastic deformation [28-30]. Adding an organic rigid body like SAN to PP may be better for impact strength than adding inorganic particles because SAN can bond with PP due to the presence of acrylonitrile [31].

Nevertheless, different from inorganic particles, the compatibility between organic particles and the polymer matrix needs to be well controlled, which would significantly affect the diameter of dispersed particles and adhesion strength (the morphology), thus causing possible changes in mechanical properties. Kim et al. [32] controlled the morphology and interfacial tension of $\mathrm{PC} /$ SAN blends with a compatibilizer, indicating that $\mathrm{PC} /$ SAN blends had minimum interaction energy as adding PC to SAN polymer. Kum et al. [33] examined the influence of PP-g-SAN on a PP/ABS system, and obtained minimum droplet size at an optimized compatibilizer ratio and enhanced the interaction between both phases, and thus subsequently affected the mechanical and morphological properties. Several scientific works have stated that the incompatibility of PP and the ABS matrix arises from huge differences in their polarity and thermal coefficients. Therefore, study of the compatible effects of SAN and PP matrix is necessary in order to systematically examine the effect of SAN on the mechanical and thermal properties of PP matrix.

Compared with ABS, SAN shows lower impact strength due to lacking butadiene, which is similar to the more rigid inorganic particles. Besides, it is easy to control the compatibility and chemical bonds with PP. However, blending styrene acrylonitrile (SAN) with PP have been much less frequently reported. Herein, in this study, we focus on comparing mechanical performances, the morphology, and thermal deformation properties of SAN/PP blends obtained by a melt-blending process using a twin-screw extruder. The contents of SAN were selected at $0,5,10,15$ and $20 \mathrm{wt} \%$ because these were expected to enhance toughness and optimize thermal deformation properties of the blends.

\section{Methods \\ Materials}

Polypropylene (PP, MFI $=27 \mathrm{~g} / 10 \mathrm{~min}$ ) was purchased from Kingfa Science and Technology. Co., Ltd. SAN (HF-1095A) was purchased from Huafeng Corporation (Guangzhou, China). Chlorinated paraffin (CP) was obtained from Shanghai Sunny New Technology Development (Shanghai, China). Styrene maleic anhydride (SMA) bought from Shanghai Sunny New Technology Development (Shanghai, China). The starting compositions of the respective blends are presented in Table 1. All materials used in the blends were first dried at $80^{\circ} \mathrm{C}$ and then accurately weighed.

\section{Synthesis of SAN/PP blends}

The SAN/PP blends were prepared by melt-blending process with slight modifications [23, 34]. Initially, SAN, PP, SMA, and CP were pre-blended in a high speed mixer (SHR-10A, Coperion Heng AO Machinery, Nanjing, China). Then the mixtures were melted and blended using a twin screw co-rotating extruder (SHJ36, Coperion Heng AO Machinery, Nanjing, China) with L/D 40 operating at a speed of $30 \mathrm{rpm} / \mathrm{min}$. Compounding was carried out at 165, 175, 180, 185, 190, 195 and $190{ }^{\circ} \mathrm{C}$ in sequential heating zones was cooled, cut, and then dried at $90{ }^{\circ} \mathrm{C}$ for $8 \mathrm{~h}$ to remove all the water

Table 1 The composition of pure PP and SAN/PP blends

\begin{tabular}{lllll}
\hline Blends & PP (wt\%) & SAN (wt\%) & SMA (wt\%) & CP (wt\%) \\
\hline SAN/PP-0 & 97.5 & 0 & 2 & 0.5 \\
SAN/PP-5 & 92.5 & 5 & 2 & 0.5 \\
SAN/PP-10 & 87.5 & 10 & 2 & 0.5 \\
SAN/PP-15 & 82.5 & 15 & 2 & 0.5 \\
SAN/PP-20 & 77.5 & 20 & 2 & 0.5 \\
\hline
\end{tabular}


before characterization. Some extrudate was immediately molded in an injection molding machine (TC-150-P, Tiancheng Machinery Co. Ltd, China) at 180, 195, and $205^{\circ} \mathrm{C}$ in sequential zones from hopper to mold to obtain dog-bone shaped sheets of $150 \mathrm{~mm} \times 10 \mathrm{~mm} \times 4 \mathrm{~mm}$ and rectangular samples of $80 \mathrm{~mm} \times 10 \mathrm{~mm} \times 4 \mathrm{~mm}$ for mechanical (tensile, impact tests), thermal (heat deflection and Vicat softening temperatures, melt flow index test and morphological examination (scanning electron microscopy).

\section{Characterization}

The phase constituents of five blends were evaluated using an X-ray diffractometer (XRD, Philips PC-APD) with a $\mathrm{CuK \alpha}(30 \mathrm{~mA}$ and $30 \mathrm{kV})$ radiation source of $0.154 \mathrm{~nm}$ wavelength at room temperature of $25{ }^{\circ} \mathrm{C}$. The functional groups were examined using a Fourier transform infrared spectroscope (FTIR, Nicolet, 170SX, Wisconsin, USA) in the wave number range of $400-4000 \mathrm{~cm}^{-1}$ by pressing the samples and $\mathrm{KBr}$ into a membrane. The thermal properties of the blends were determined using a differential scanning calorimeter; samples were subjected to a stream of pure nitrogen flowing at a rate of $50 \mathrm{ml} / \mathrm{min}$ and heated at $10{ }^{\circ} \mathrm{C} / \mathrm{min}$ from 25 to $220^{\circ} \mathrm{C}$.

The degree of crystallinity $\left(\mathrm{X}_{\mathrm{c}}\right)$ of PP was determined by calculating the ratio of heat of fusion $\left(\triangle \mathrm{H}_{\mathrm{m}}\right)$ of the specimens to the heat of fusion of $100 \%$ crystalline PP $\left(\triangle \mathrm{H}_{\mathrm{m}}=207 \mathrm{~J} / \mathrm{g}\right)[35]$.

\section{Mechanical properties testing}

Measurements of the tensile strength and elongation at break of all specimens were carried out on a universal testing machine (WDW-100, Tianjin Meites Testing machine factory, China) using dog bone-shaped specimens $(150 \mathrm{~mm} \times 10 \mathrm{~mm} \times 4 \mathrm{~mm})$ according to the standard of GB/T 1040.2-2006 at room temperature. The assay was performed under a liner deformation loading rate of $50 \mathrm{~mm} / \mathrm{min}$ until mechanical failure occurred. Three replicates were performed for each measurement.

The impact strength was assessed on a beam impact testing machine (XJJ-5, Chengde Shipeng Testing Machine Co. LTD, China) at ambient temperature using rectangular samples $(80 \mathrm{~mm} \times 10 \mathrm{~mm} \times 4 \mathrm{~mm})$ in terms of GB/T 1043.1-2008 standard. For each measurement, three specimens were used.

\section{Morphological observations}

The morphologies of PP and SAN/PP blends containing 10 or $20 \mathrm{wt} \%$ SAN were characterized by scanning electron microscopy (SEM, S-900, Hitachi) at magnifications of $2000 \mathrm{X}$ and 10,000X, operating at an accelerating voltage of $5 \mathrm{kV}$. The specimens were cryogenically fractured in liquid nitrogen, and the fracture surfaces were coated with platinum to a depth of $10 \AA$.

\section{Thermal deformation behavior and viscosity analysis}

The melt flow indexes (MFI) of PP and SAN/PP blends were determined using a flow rate meter (XNR-400B, Chengde Shipeng Testing Machine co. LTD, China) using particle specimens at $230{ }^{\circ} \mathrm{C}$ with a loading weight of $2.16 \mathrm{~kg}$ in accordance with GB/T 3682-2000 standard.

The thermal deformation properties of PP and SAN/ PP blends were assessed using a thermal deformation and Vicat softening temperature tester (XWB-300B, Chengde Shipeng Testing Machine co. LTD, China) with silicone oil as warming medium. Rectangular samples $(80 \mathrm{~mm} \times 10 \mathrm{~mm} \times 4 \mathrm{~mm})$ were scanned from $25^{\circ} \mathrm{C}$ to deformation temperature at a heating rate of $120^{\circ} \mathrm{C} / \mathrm{h}$ under a perpendicular loading weight of $75 \mathrm{~g}$ (bending normal stress: $0.45 \mathrm{MPa}$ ) in line with GB/T1634.2-2004. The Vicat softening temperatures of the specimens were measured under a loading weight of $1000 \mathrm{~g}$, heating from $25{ }^{\circ} \mathrm{C}$ to Vicat softening temperature at a rate of $50{ }^{\circ} \mathrm{C} / \mathrm{h}$ in terms of GB/T 1633-2000.

\section{Results and discussion}

\section{XRD studies of SAN/PP blends}

It is known that PP is a polymorphous crystal, showing three crystalline forms designated as $\alpha$-phase, $\beta$-phase, and $\gamma$-phase. $\alpha$-phase is the dominanting; $\beta$-phase and $\gamma$-phase are induced when nucleating agents are added into the PP matrix [23-25]. The XRD patterns of pure PP and SAN/PP blends are displayed in Fig. 1. Crystal peaks can be clearly observed at $2 \theta$ values of around $14.2^{\circ}, 17.1^{\circ}, 19.2^{\circ}$ and $21.7^{\circ}$ for all specimens. These peaks were consistent with the monoclinic $\alpha$-form of PP crystals for (110), (040), (130) and (131) planes, respectively [36]. However, the peaks of $\beta$ and $\gamma$-crystalline phases did not occur, and there were no significant difference for all specimens; these results indicate that SAN has no obvious effect on crystallization behavior of PP.

\section{FTIR analysis of SAN/PP blends}

Figure 2 shows the FTIR spectra of pure PP and SAN/ PP blends. The characteristic peaks of PP were observed for all specimens. The absorption peaks of 2967.8 and $2918.4 \mathrm{~cm}^{-1}$ are consistent with symmetric and asymmetric stretching vibrations of $\mathrm{CH}_{2}$ or $\mathrm{CH}_{3}$, and the peak at $2854.2 \mathrm{~cm}^{-1}$ corresponds to symmetric and asymmetric vibrations of $\mathrm{CH}_{3}[37,38]$. In addition, the peak around 1462.5 and $1377.2 \mathrm{~cm}^{-1}$ was assigned as the $\mathrm{CH}_{3}$ or $\mathrm{CH}_{2}$ deformation vibration. In contrast to pure PP, the FTIR spectrum of SAN/PP blends was clearly different, exhibiting two additional peaks around 2237.2 and $3045.7 \mathrm{~cm}^{-1}$ that correspond to $\mathrm{C}-\mathrm{N}$ stretching 


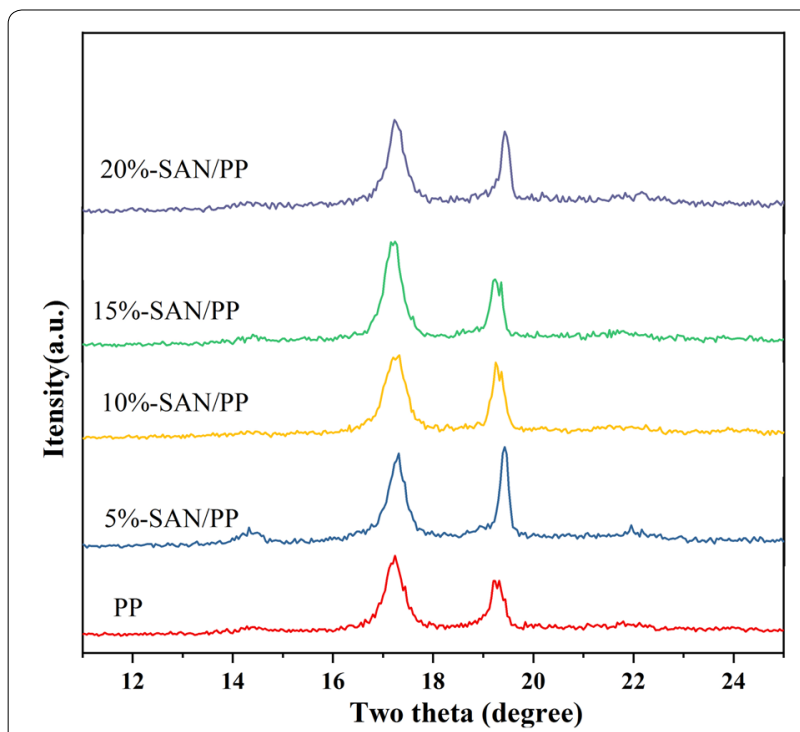

Fig. 1 XRD patterns of PP and SAN/PP blends vibrations in acrylonitrile and $\mathrm{C}-\mathrm{H}$ stretching vibrations of benzene in styrene of SAN [38]. In other words, the differences in the FTIR spectra reflect or correspond to the presence of SAN in SAN/PP blends.

\section{DSC analysis of SAN/PP blends}

Melting temperatures $\left(\mathrm{T}_{\mathrm{m}}\right)$ of pure PP and SAN/PP blends were examined by DSC. As shown in Fig. 3, the melting point of these specimens were different. The endothermic melting peak occurred at about $165.3^{\circ} \mathrm{C}$ for pure PP, which was lower than any of the SAN/PP blends (see Table 2). A similar trend was observed in heat fusion $\left(\triangle \mathrm{H}_{\mathrm{m}}\right)$ results, showing that the values of SAN/PP blends containing SAN of 10, 15 and $20 \mathrm{wt} \%$ (about 56.6, $48.3,51.3 \mathrm{~J} / \mathrm{g}$ respectively) were significantly lower than that of pure PP (about $75.5 \mathrm{~J} / \mathrm{g}$ ) and SAN/PP blends containing SAN of $5 \mathrm{wt} \%$ (about $71.0 \mathrm{~J} / \mathrm{g}$ ). In other words, 10 wt $\%$ or higher content of SAN in a SAN/PP blend lowers the degree of crystallinity. Only one endothermic melting point was observed, demonstrating that SAN/PP blends

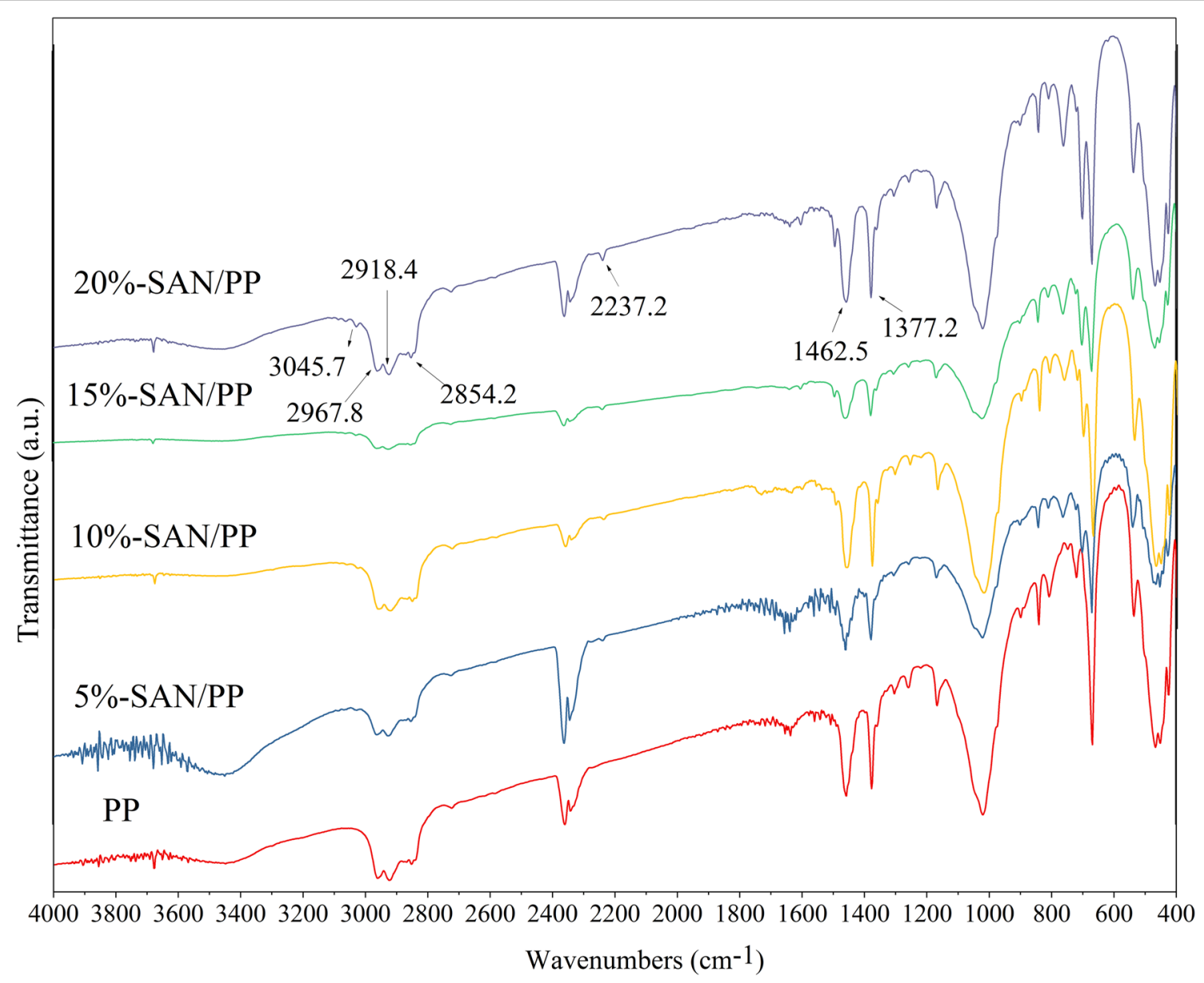

Fig. 2 FTIR spectra of PP and SAN/PP blends 


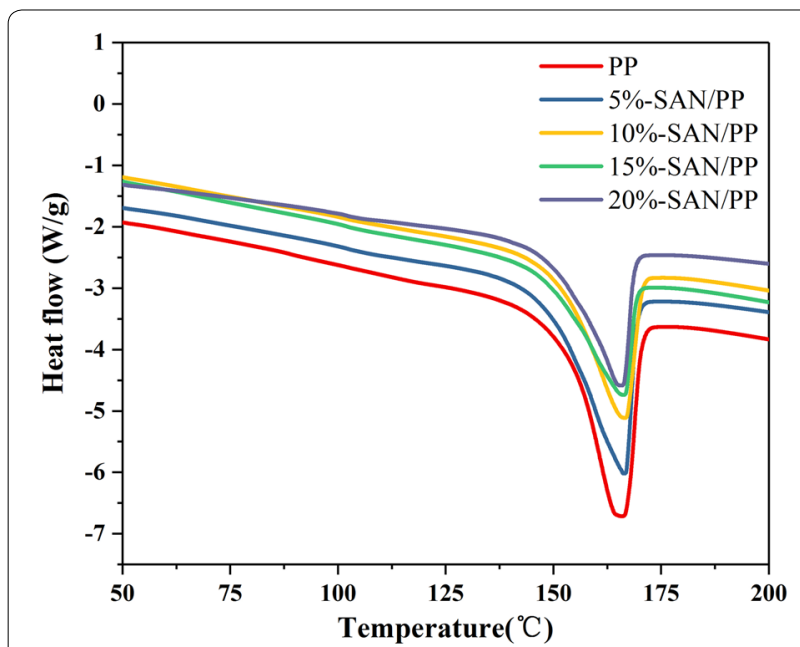

Fig. 3 DSC patterns of PP and SAN/PP blends

Table 2 Melting and crystallization parameters of pure PP and SAN/PP blends

\begin{tabular}{llll}
\hline Blends & $\mathbf{T}_{\mathbf{m}}\left({ }^{\circ} \mathbf{C}\right)$ & $\boldsymbol{\Delta}_{\mathbf{m}}(\mathbf{J} / \mathbf{g})$ & $\mathbf{X}_{\mathbf{c}}(\%)$ \\
\hline SAN/PP-0 & 166.5 & 75.5 & 36.5 \\
SAN/PP-5 & 167.2 & 71.0 & 34.3 \\
SAN/PP-10 & 167.8 & 56.6 & 27.4 \\
SAN/PP-15 & 168.3 & 48.3 & 23.4 \\
SAN/PP-20 & 167.0 & 51.3 & 24.8 \\
\hline
\end{tabular}

crystallized in only one form, and this is consistent with the XRD patterns.

These results indicate that SAN has no obviously effect on crystal form but lower the degree of crystallinity of PP. This is different from ABS/PP blends synthesized by several other researchers which obtained $\beta$-crystalline phase $[16,17]$. Mastan et al. [23] showed that the $\beta$ crystal form of PP crystals occurrs in HNTs- and IFR-filled 80/20 (wt/ wt) PP/ABS blends and their composites, and reasoned that ABS and SEBS-g-MA acted as a $\beta$-nucleating agent and the similar depiction by Nayak et al. [16]. However, in our study, SMA and SAN had been added into the PP matrix but did not facilitate the formation of the $\beta$-crystal form. This likely correlates with the absence of butadiene for SAN (Fig. 3).

\section{Scanning electron microscopy}

The morphologies of fracture surfaces of pure PP and SAN/PP blends containing 10 and 20 wt $\%$ SAN were investigated by SEM in order to examine the phase compatibility and distribution of SAN in the PP matrix. As shown in Fig. 4, three different kinds of phase morphologies were observed. Some nano-particles with a particle size of 50-900 nm were dispersed on the surface of PP matrix for SAN/PP blends containing $10 \mathrm{wt} \%$ (Fig. 4b, e). This was similar with the nanocomposite-doped rigid inorganic filler particles with the fracture morphology of particles distributed on the surface of polymer matrix [39-41]. An irregular structure like sea-island was

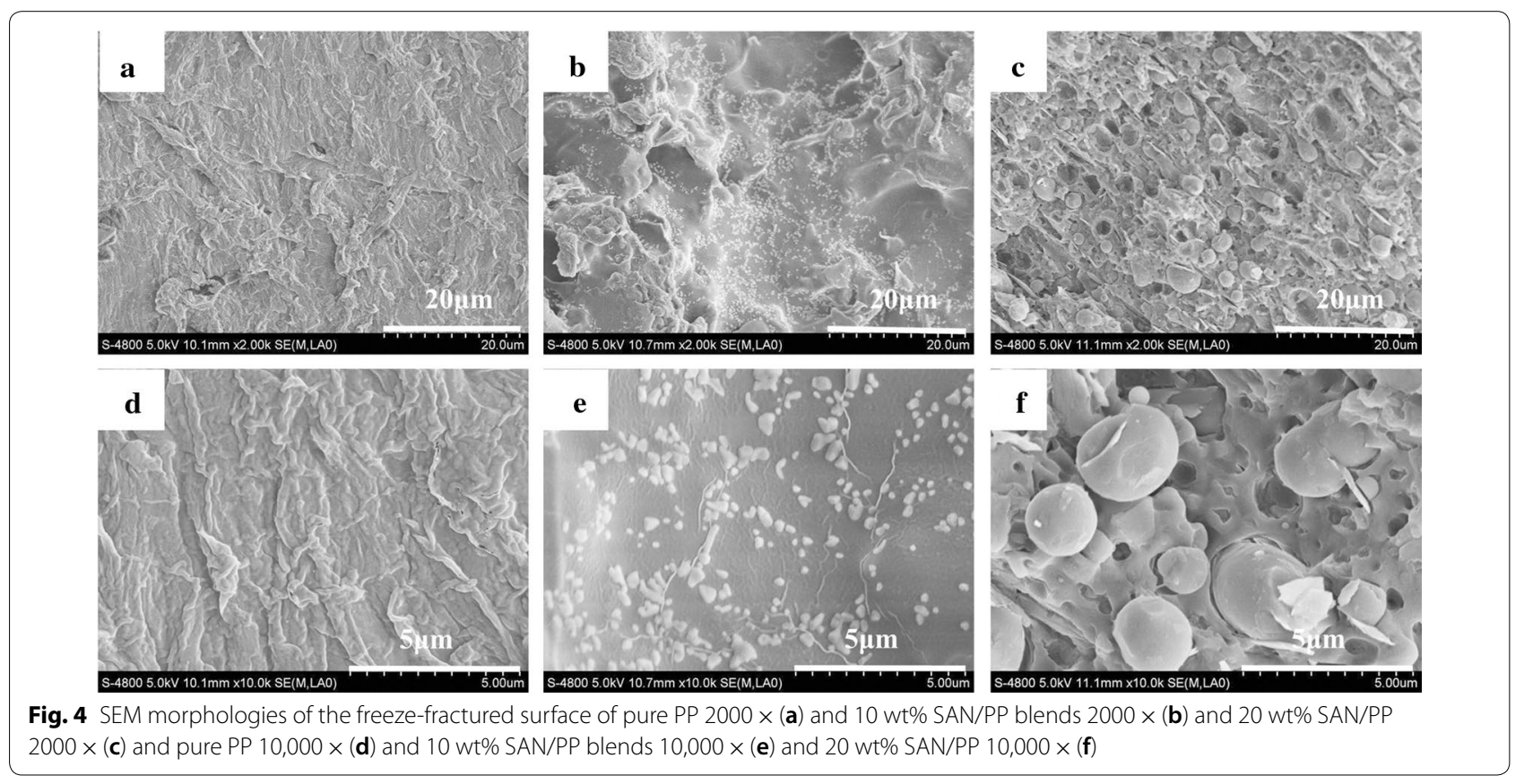


distinctly observed on surface of SAN/PP blends containing $20 \mathrm{wt} \%$ SAN (Fig. 4c). It was mostly covered by SAN spherical droplets and dark holes like meteor crater with the size of $0.5-4 \mu \mathrm{m}$ (Fig. 4f), indicating the partial miscibility (or intermixing miscibility window) typical of SAN/ PP blends [42].

SAN/PP blends containing $10 \mathrm{wt} \%$ SAN exhibited the presence of nanoparticles dispersed on the surface, and it was confirmed to be amorphous with no indication of crystal phase by the result of XRD spectrum (Fig. 1). In addition, FTIR spectra (Fig. 2) demonstrated the presence of a $\mathrm{C}-\mathrm{N}$ band in acrylonitrile and a $\mathrm{C}-\mathrm{H}$ benzene band in styrene of SAN for SAN/PP blends with $10 \mathrm{wt} \%$ SAN. All of these results confirmed that the nanoparticles were mostly correspond to SAN and that was taken as an indication that SAN and PP were utterly immiscible with each other. However, SAN/PP blends containing 20 wt\% SAN showed partial miscibility (or intermixing miscibility), between SAN and pure PP, due to unfavorable thermodynamics. And there were many voids on the surface of the specimens, which indicated that the interfacial adhesion of SAN and PP is poor. During the impact fracture, the SAN droplets were pulled out. Some of the spherical droplets which were not pulled out may have arisen from the interaction between the nitrile group of SAN and the maleic anhydride group of SMA [42]. This is consistent with most other researches [43-46]. For example, Kubade and Tambe [36] showed that $80 / 20$ (wt/wt) PP/ABS blend formed coarser matrix-droplet morphology. The result of nanoparticles forming on the continuous surface of SAN/PP blends with $10 \mathrm{wt} \%$ SAN is not in agreement with the previous researches related to binary blends. For instance, Krache et al. [42] showed that 10 $\mathrm{wt} \%$ ABS phase appeared as spherical inclusions in the PC phase matrix. Kim et al. [32] demonstrated that interfacial tension and particle size were further reduced by adding compatibilizer to the PC/SAN blends. Kum et al. [33] obtained the minimum size of the dispersed droplets with an optimized addition compatibilizer ratio on $\mathrm{PP} / \mathrm{ABS}$ system, which enhanced the interaction between both phases. Thus, in our study, the different morphologies of SAN/PP blends containing $10 \mathrm{wt} \%$ SAN and 20 wt\% SAN suggested a likely relationship between the size of SAN particles and the compatibility (interaction between SAN and PP).

\section{Thermal deformation behavior and viscosity analysis}

It has been reported that the addition of solid particles affects the melting viscosity of polymers [47]. The melt flow indexes of the pure PP and four specimens of SAN/PP blends are shown in Fig. 5. It was found that the curve of MFI values of all specimens appeared as a "V" type. The MFI value reduced sharply as the content

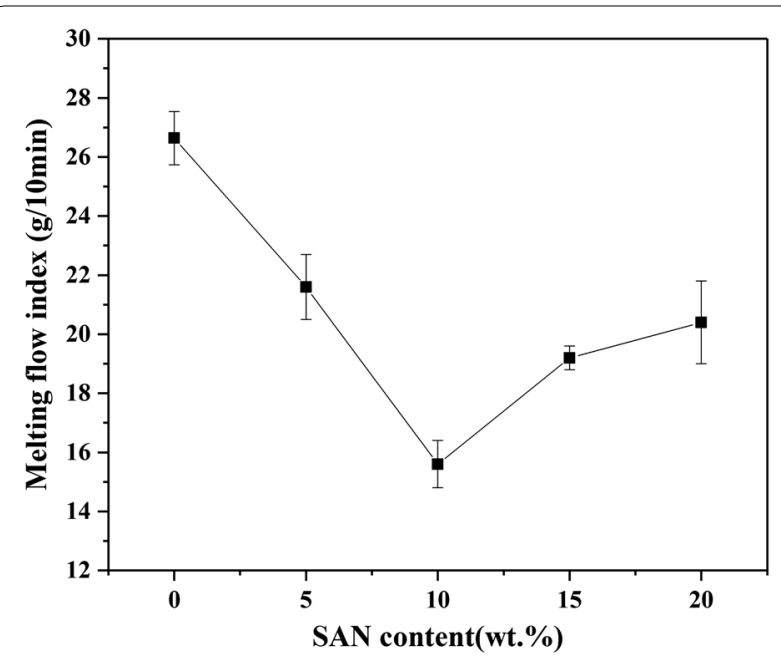

Fig. $5 \mathrm{MFI}$ values of PP and SAN/PP blends

of SAN increased, at low concentrations of $10 \mathrm{wt} \%$ SAN, followed by an increase observed in the SAN/PP blends with SAN content from 10 to $20 \mathrm{wt} \%$. Overall, the MFI values of all SAN/PP blends were lower than that of pure PP. The similar result was also obtained by other researches with rigid-inorganic/polymer composites [48, 49], in which adding filler particles lowered the MFI. Furthermore, solid particles, such as pigments, fillers or additives, have been reported to affect important rheological properties of polymers, mainly viscosity and deviation from the Newtonian flow [50].

The Heat Deflection Temperature (HDT) is considered as a function of the temperature of certain creep compliance after the material has been subjected to a certain program [42]. Figures 6 and 7 show the HDT and Vicat Softening Temperature (VST) of pure PP and all SAN/PP blends specimens, respectively. As shown in Fig. 6, the heat deflection temperatures of specimens containing 5 and $10 \mathrm{wt} \%$ SAN were distinctly higher than that of pure PP but no obviously elevation was observed for specimens containing 15 to $20 \mathrm{wt} \%$ SAN. As for the Vicat points (Fig. 7), the values of all SAN/PP blends were higher than that of pure PP, while decreased as the SAN content increased from 5 to 20 wt\%.

This result suggests that SAN/PP blends exhibit higher HDT and VST values than pure PP, especially for blends with low concentration of SAN (i.e., under 10 $\mathrm{wt} \%)$. This is not consistent with some other researches, for instance, Krache et al. [42]. showed that the more ABS was added to PC, the lower the HDT and VST values. This difference is likely arising from different phase morphology, in our study, the surface of SAN/PP blends with $10 \mathrm{wt} \%$ SAN was covered by rigid nanoparticles. 


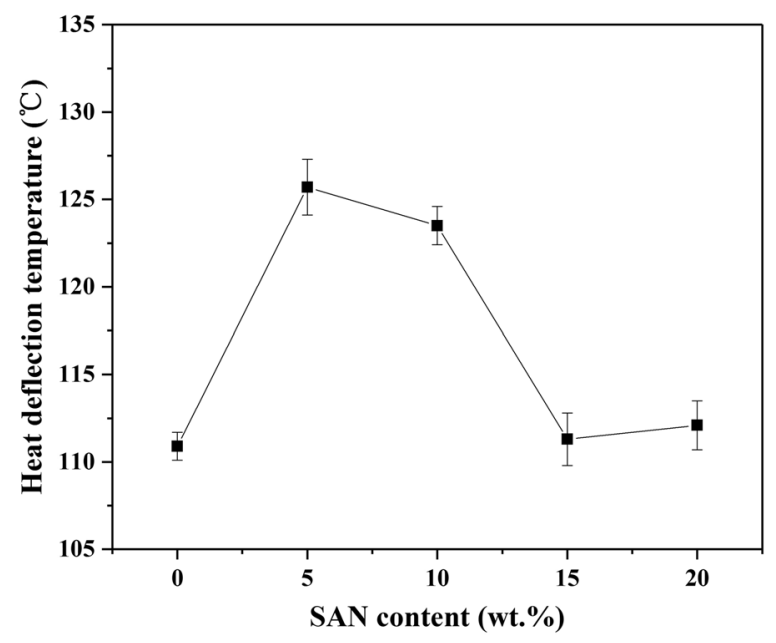

Fig. 6 HDT values of PP and SAN/PP blends

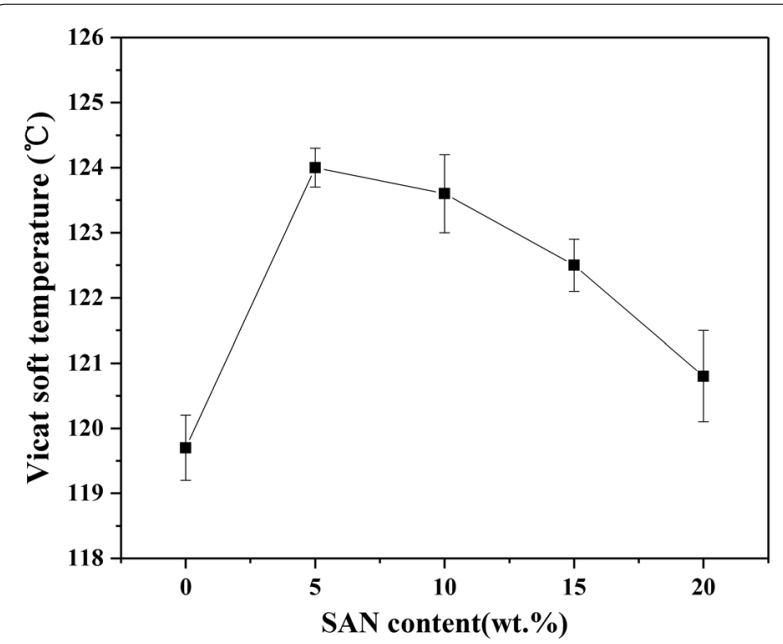

Fig. 7 VST values of PP and SAN/PP blends

There are some studies, which claims that rigid particle fillers can increase heat distortion temperature of polymers. For example, Qiang and Gubbels et al. [51, 52] demonstrated that rigid fillers improved the heat distortion temperature of polymer blends.

\section{Mechanical properties}

\section{Impact strength of SAN/PP blends}

The effects of SAN fillers on the mechanical properties of pure PP are shown in Figs. 8, 9, 10. Figure 8 displays the charpy impact properties of pure PP and SAN/PP blends. Impact strength improved significantly as the amount of SAN increased from 0 to $10 \mathrm{wt} \%$, and then decreased rapidly with the addition of SAN up to $20 \mathrm{wt} \%$. Specifically, the impact strength of SAN/PP blends containing

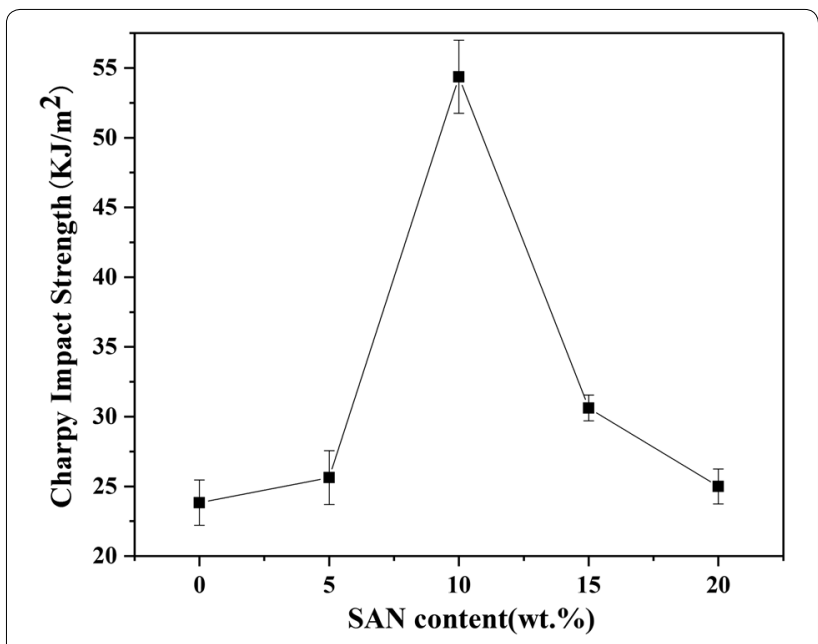

Fig. 8 Impact strength of PP and SAN/PP blends

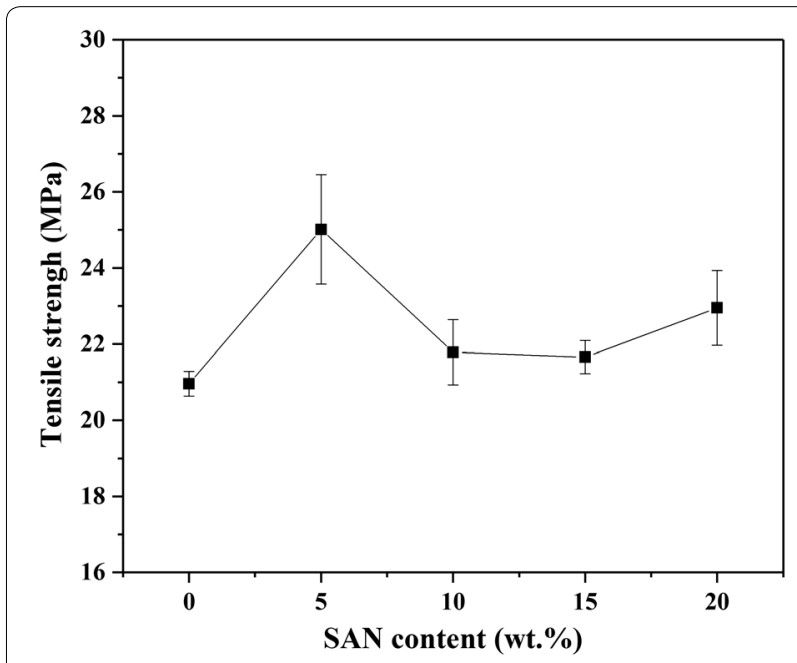

Fig. 9 Tensile strength of PP and SAN/PP blends

$10 \mathrm{wt} \%$ SAN was elevated to $31.59 \mathrm{~kJ} / \mathrm{m}^{2}$, which was 2.3 times higher than that of pure PP. The impact strength of the other blends containing 5, 15 and $20 \mathrm{wt} \%$ SAN showed an increase of $1.79,6.83$ and $1.17 \mathrm{~kJ} / \mathrm{m}^{2}$, respectively, in contrast to the pure PP. Overall, SAN/PP blends exhibited higher impact strength, especially for blends containing 10 and $15 \mathrm{wt} \%$ of SAN.

Impact properties play a critical role in engineering applications. A super-toughened SAN/PP blends with impact strength 2.3 times higher than that of pure PP was achieved by adding $10 \mathrm{wt} \%$ SAN. The result reveals that the addition of SAN can significantly improve toughness. This enhancement is likely owing to its phase morphology, with rigid nanoparticles dispersed on the PP surface (Fig. 4) resulting from the incompatibility of SAN and PP. 


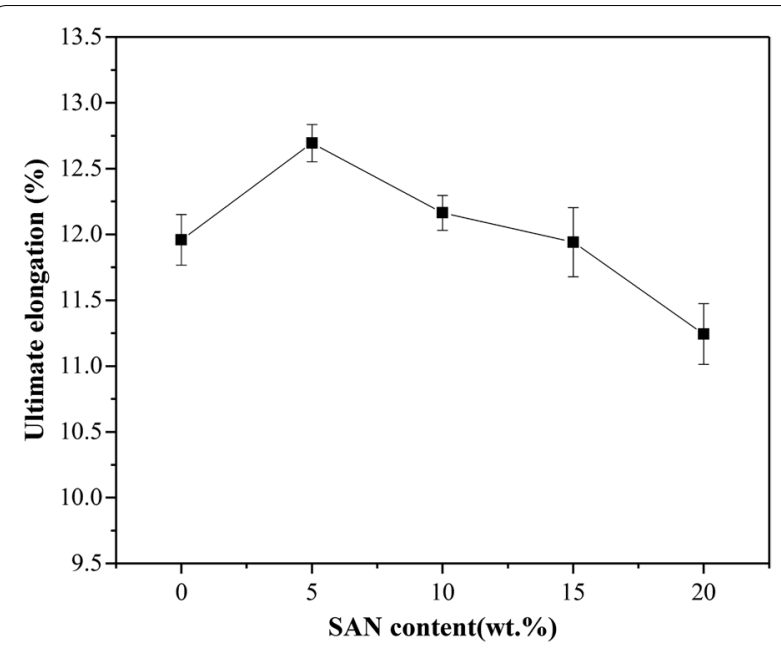

Fig. 10 Ultimate elongation of PP and SAN/PP blends

There are some scientific studies, which claim that the addition of rigid particle fillers can increase the impact strength of polymers [28-30]. Sahnoune et al. [53] demonstrated that the incorporation of $\mathrm{CaCO}_{3}$ can significantly enhance the stiffness of HDPE/PS blends. Hong et al. [40] showed that the izod impact strength of pure PP is significantly enhanced by adding nano- $\mathrm{SiO}_{2}$ particles. García-López et al. [5] claimed that, for a nanocomposite subjected to impact loading, the interfacial regions were able to resist crack propagation more effectively than the polymer matrix. Some researchers have claimed that rigid particle fillers in a polymer matrix under tension would lead to concentrated stress followed by debonding and shear yielding [29]. Besides, the stresses applied to the polymer increase with the increase of the resistance to separation (adhesion strength) between matrix and filler and this resistance is related to particle size. Small particles are desirable when the adhesion between matrix and filler is poor [5]. Although the adhesion needs to be further studied, the particle size in our study is small, and this smallness may have increased resistance to separation as a result of an enhancement of impact properties.

Although the impact strength of SAN/PP blends with 15 and $20 \mathrm{wt} \%$ SAN was much lower than that of blends with $10 \mathrm{wt} \% \mathrm{SAN}$, when compared to that of pure PP the impact strength of them was slightly improved. This may be attributed to the "sea-island" structure with spherical droplets and dark holes covering the surface of SAN/ PP blends. When the impact load was applied to SAN/ PP blends, the droplets were pulled out as the load transferring to, followed by void growth at interface or cavitation of SAN, and finally resulted in more energy absorption [23]. On the other hand, it is well known that the mechanical properties of thermoplastics such as tensile, compressive, shear properties and especially impact strength are effected by the degree of crystallinity because the tight molecular arrangement resulting from higher crystallinity will lead to a decline of porosity, restrict the activity of the molecular chain, and ultimately decrease impact strength [54, 55]. Overall, our results showed that SAN/PP blends exhibited higher impact strength than pure PP, but the properties varied according to the amount of SAN. The morphologies of SAN/ PP blends with 10 and $20 \mathrm{wt} \%$ SAN and and the fact that SAN/PP blends lower crystallinity of PP suggest a close relationship between impact strength, morphology, and crystallinity of SAN/PP blends.

\section{Tensile strength of SAN/PP blends}

As shown in Figs. 9 and 10, the effects of SAN on the tensile strength and ultimate elongation of blends were examined. It can be seen that the SAN/PP blends containing $5 \mathrm{wt} \%$ of SAN exhibited a tensile strength of 25.0 MPa, which was higher than that of pure PP $(20 \%$ over than pure PP), and had an higher elongation of $12.7 \%$. As the SAN concentration increased, the tensile strength was slightly higher than that of pure PP. When the concentration increased up to $20 \mathrm{wt} \%$, the elongation was reduced to $11.24 \%$. Generally, $5 \mathrm{wt} \%$ of SAN in SAN/ PP blends showed a maximum values of tensile strength and ultimate elongation, which was attributed to the refined dispersion of nanoparticles in PP matrix [56].

\section{Conclusion}

In summary, we demonstrated that SAN/PP blends with different content of SAN showed different morphologies, mechanical performances and thermal deformation properties. According to the XRD, FTIR and DSC analyses, SAN had no obviously effect on crystal form but reduced the crystallinity of PP. Thermal deformation and viscosity assays showed that the addition of SAN to PP increased the viscosity of blends and HDT and VST values were enhanced for all SAN/PP blends. The SAN/PP blends with $10 \mathrm{wt} \%$ SAN revealed the presence of nanoparticles dispersed on the surface, while SAN/PP blends with $20 \mathrm{wt} \%$ SAN exhibited sea-island morphology. All SAN/PP blends showed higher impact strength compared to pure PP, especially for SAN/PP blend containing $10 \mathrm{wt} \%$ SAN. The reason for the significant increase was most likely related to formation of rigid nanoparticles and the slight increase for SAN/PP blends with 15 and 20 $w t \%$ SAN was likely owing to the sea-island morphology and the decrease of crystallinity.

\section{Authors' contributions}

YJL and TY initiated and designed the review. XLW and LZ collected the literatures and drafted the manuscript. All authors contributed to literatures 
analysis and manuscript finalization. All authors read and approved the final manuscript.

\section{Author details}

${ }^{1}$ School of Materials Engineering, Chengdu Technological University, Chengdu 611730, China. ${ }^{2}$ School of Chinese Medicine, Hong Kong Baptist University, Hong Kong, Special Administrative Region, People's Republic of China.

\section{Acknowledgements}

This work was partially supported by the National Natural Science Foundation of China (81673691, 81603381), the Guangdong Natural Science Foundation (2016A030313008), and the Shenzhen Science and Technology Innovation Committee (JCYJ20160518094706544).

\section{Competing interests}

The authors declare that they have no competing interests.

\section{Availability of data and materials}

All data are fully available without restriction.

\section{Consent for publication}

All authors agree to publish this article.

\section{Ethics approval and consent to participate}

Not applicable.

\section{Funding}

This work was the Guangdong Natural Science Foundation (2016A030313008) and the Shenzhen Science and Technology Innovation Committee (JCYJ20160518094706544).

\section{Publisher's Note}

Springer Nature remains neutral with regard to jurisdictional claims in published maps and institutional affiliations.

\section{Received: 21 February 2018 Accepted: 26 June 2018}

Published online: 09 July 2018

\section{References}

1. Thakur S, Verma A, Sharma B, Chaudhary J, Tamulevicius S, Thakur V (2018) Recent developments in recycling of polystyrene based plastics. Curr Opin Green Sustain Chem 13:32-38

2. Michalska-Pożoga I, Rydzkowski T, Mazur P, Sadowska O, Thakur V (2017) Recent developments in recycling of polystyrene based plastics. Vacuum 146:641-648

3. Thakur V, Tan E, Lin M, Lee P (2011) Polystyrene grafted polyvinylidenefluoride copolymers with high capacitive performance. Polym Chem UK 2:2000-2009

4. Chan C, Wu J, Li J (2002) Polypropylene/calcium carbonate nanocomposites. Polymer 43:2981-2992

5. García-López D, Picazo O, Merino J (2003) Polypropylene-clay nanocomposites: effect of compatibilizing agents on clay dispersion. Eur Polym J 39:945-950

6. Thakur V, Grewell D, Thunga M, Novel Kessler M (2014) Composites from eco-friendly soy flour/SBS triblock copolymer. Macromol Mater Eng 299:953-958

7. Thakur V, Vennerberg D, Kessler M (2014) Green aqueous surface modification of polypropylene for novel polymer nanocomposites. ACS Appl Mater Inter 6:9349-9356

8. Wahit M, Hassan A, Mohd Ishak Z (2005) The effect on polyethyleneoctene elastomer on the morphological and mechanical properties of polyamide-6/polypropylene nanocomposites. Polym Polym Compos 13:795-805

9. Ghasem N, Pierre G, Charles D (2007) Microstructrue-properties correlations in dynamically vulcanized nanocomposites thermoplastic elastomers based on PP/EPDM. Polym Eng Sci 47:207-217
10. Ding H, Guo L (2015) Effect of annealing temperature on low-temperature toughness of $\beta$-nucleated polypropylene randomcopolymer/ethylene-propylened-diene terpolymer blends. Chin J Polym Sci 33:256-264

11. Liu B, Shang Y, Song Y, Zheng Q (2013) Influences of compatibilizers on rheology and mechanical properties of propylene randomcopolymer/ styrene-ethylene-butylene-styrene block copolymer/organic-montmorillonite nanocomposites. J Appl Polym Sci 129:973-982

12. Martinatti F, Ricco T (1994) High-rate fracture toughness of polypropylene-based, hybrid, particulate composites. J Mater Sci 29:442-448

13. Kumar A, Depan D, Singh R (2009) Nanoscale particles for polymer degradation and stabilization-trends and future perspectives. Prog Polym Sci 34:479-515

14. Mai J, Zhang M, Rong M, Zhang M (2012) Crystallization behavior and mechanical properties of nano- $\mathrm{CaCO}_{3} / \beta$-nucleated ethylene-propylene random copolymer composites. Express Polym Lett 16:739-749

15. Li Y, Zhang G, Fu X, Wu G (2015) Preparation and properties of coreshell particles filled $\beta$-nucleated polypropylene random copolymer composites. Polym Polym Compos 23:1-9

16. Bonda S, Mohanty S, Nayak S (2014) Influence of compatibilizer on mechanical, morphological and rheological properties of PP/ABS blends. Iran Polym J 23:415-425

17. Luo Z, Lu Q, Ma F, Jiang Y (2014) The effect of graft copolymers of maleic anhydride and epoxy resin on the mechanical properties and morphology of PP/ABS blends. J Appl Polym Sci 131:40898-40908

18. Li D, Demin J, Zhou P (2004) Compatibilization of polypropylene/nylon 6 blends with a polypropylene solid-phase graft. J Appl Polym Sci 93:420-427

19. Shashidhara G, Biswas D, Subhalakshmi P (2009) Effect of PP-g-MAH compatibilizer content in polypropylene/nylon-6 blends. Polym Bull 63:147-157

20. Adriana M, atrícia PS, Nicole R (2013) Linear viscoelastic behavior of compatibilized PMMA/PP blends. J Appl Polym Sci 129:1280-1289

21. Yin Z, Zhang X, Yin J (1998) Effects of the compatibilizer PP-g-GMA on morphology and mechanical properties of PP/PC blends. Polymer 39:547-551

22. Kamelian F, Saljoughi E, Shojaee Nasirabadi P (2017) Modifications and research potentials of acrylonitrile/butadiene/styrene (ABS) membranes: a review. Polym Compos 1:1-12

23. Mastan S, Tambe P, Malathi M (2017) Influence of halloysite nanotubes and intumescent flame retardant on mechanical and thermal properties of 80/20 (wt/wt) PP/ABS blend and their composites in the presence of dual compatibilizer. J Thermoplast Compos 1:1-21

24. Wang C, Zhang Z, Du Y (2012) Effect of acrylonitrile-butadiene-styrene copolymer (ABS) on $\beta$-nucleation in $\beta$-nucleated polypropylene/ABS blends. Polym Bull 69:847-859

25. Mariana I, Triantou A (2014) Thermal stability and crystallization behavior of modified ABS/PP nanocomposites. Int J Chem Nucl Metall Eng 8:973-978

26. Arostegui A, Sarrionandia M, Aurrekoetxea J (2006) Effect of dissolution-based recycling on the degradation and the mechanical properties of acrylonitrile-butadiene-styrene copolymer. Polym Degrad Stab 27:2768-2774

27. Jin F, Lu S, Song Z (2010) Effect of rubber contents on brittle-tough transition in acrylonitrile-butadiene-styrene blends. Mater Sci Eng A 527:3438-3441

28. Pavlidou D, Vassiliou A (2005) Mechanical properties and morphological examination of isotactic polypropylene/SiO2 nanocomposites containing PP-g-MA as compatibilizer. New J Phys 10:190-193

29. Berlin A, Volfson S, Enikolopian N (1986) Principles of polymer composites. Spring, Heilderberg

30. Dijkstra P, Huétink J (2002) A microscopy study of the transition from yielding to crazing in polypropylene. Polym Eng Sci 42:152-160

31. Markin C, Leverne H (1980) Polypropylene/ABS terpolymer blends. Mixing and mechanical properties. J Appl Polym Sci 25:2451-2466

32. Kim J, Kim M, Kim C (2014) Control of morphology and interfacial tension of PC/SAN blends with compatibilizer. Korea Aust Rheol J 13:125-130

33. Kum C, Sung Y, Kim Y (2007) Effects of compatibilizer on mechanical, morphological, and rheological properties of polypropylene/poly (acrylonitrile-butadiene-styrene blends. Macromol Res 15:308-314 
34. Lu Q, Macosko C (2004) Comparing the compatibility of various functionalized polypropylenes with thermoplastic polyurethane (TPU). Polymer 45:1981-1991

35. Wunderlich B (1990) Thermal analysis. Academic Press, New York 22

36. Kudabe P, Tambe P (2016) Influence of halloysite nanotubes (HNTs) on morphology, crystallization, mechanical and thermal behaviour of PP/ ABS blend and their composites in presence and absence of dual compatibilizer. Compos Interface 5:433-451

37. Aid S, Eddhahak A, Ortega Z, Froelich D, Tcharkhtchi A (2017) Experimental study of the miscibility of ABS/PC polymer blends and investigation of the processing effect. J Appl Polym Sci 134:44975

38. Li N, Xia Y, Mao Z (2012) Influence of antimony oxide on flammability of polypropylene/intumescent flame retardant system. Polym Degrad Stab 97:1737-1744

39. Garcia M, Vliet G, Jain S (2004) Polypropylene/SiO2 nanocomposites with improved mechanical properties. Rev Adv Mater Sci 6:169-175

40. Hong Y, Zhang X, Qu C (2007) Largely improved toughness of PP/EPDM blends by adding nano- $\mathrm{SiO}_{2}$ particles. Polymer 48:860-869

41. Hricová M, Marcinčin A, Ujhelyiová A (2010) The effect of additives on rheological properties of PP/SiO2 composites. In: International Textile Conference TEXCO

42. Krache R, Debbah I (2011) Some mechanical and thermal properties of PC/ABS blends. Mater Sci Appl 2:404-410

43. Triantou M, Stathi K (2014) Rheological and thermomechanical properties of graphene/ABS/PP nanocomposites. Metall Mater Eng 8:951-956

44. Hom S, Bhattacharyya A, Khare R (2009) PP/ABS blends with carbon black: morphology and electrical properties. J Appl Polym Sci 112:998-1004

45. Rupesh A, Bhattacharya A, Kulkarni A (2011) Melt mixed polypropylene/ acrylonitrile-butadiene-styrene blends with multiwall carbon nanotubes: effect of compatibilizer and modifier on morphology and electrical conductivity. J Appl Polym Sci 120:2663-2672
46. Hyung G, Yu S, Yun K (2008) Effects of PP-g-MAH on mechanical, morhological and rheological properties of polypropylene and poly (acrylonitrile-butadiene-styrene) blends. Macromol Res 17:417-423

47. Hricová M, Marcinčin A, Hoferíková A (2009) Effect of black pigments on spinning and non-uniformity of pigmented polyester fibres In: Proceeding of X. International Conference IMTEX 2009, Lodž, Poland 16: 53-56

48. Fuad M, Ismail Z, Ishak Z (1995) Mechanical properties of rice husk ash/ polypropylene composites. J Eur Polym 31:885-890

49. Ichazo M, Albano C, Gonzalez J (2001) Polypropylene/wood flour composites: treatments and properties. Compos Struct 54:207-214

50. Marcinčin A, Hricová M, Marcinčin K (2009) Study of rheological, thermal and mechanical properties of PP/organoclay composites and fibres. Fibres Text East Eur 17:22-28

51. Gubbels F, Teyssie P, Vanlathem E (1994) Selective localization of carbon black in immiscible polymer blends: a useful tool to design electrical conductive composites. Macromolecules 27:1972-1974

52. Gubbels F, Vanlathem E, Jerome R (1995) Design of electrical composites: determining the role of the morphology on the electrical properties of carbon black filled polymer blends. Macromolecules 28:1559-1566

53. Sahnoune F, Lopez Cuesta J, Crespy A (2003) Improvement of the mechanical properties of an HDPE/PS blend by compatibilization and incorporation of $\mathrm{CaCO}_{3}$. Polym Eng Sci 43:647-660

54. Brady D (1976) The crystallinity of poly (phenylene sulfide) and its effect on polymer properties. J Appl Polym Sci 20:2541-2551

55. Talbott M, Springer G, Berglund L (1987) The effects of crystallinity on the mechanical properties of PEEK polymer and graphite fiber reinforced PEEK. J Compos Mater 21:1056-1081

56. Pedrazzolia D, Khumalo V, Karger J (2014) Thermal, viscoelastic and mechanical behavior of polypropylene with synthetic boehmite alumina nanoparticles. Polym Test 35:92-100

\section{Submit your manuscript to a SpringerOpen ${ }^{\circ}$ journal and benefit from:}

- Convenient online submission

- Rigorous peer review

- Open access: articles freely available online

- High visibility within the field

Retaining the copyright to your article

Submit your next manuscript at springeropen.com 